\title{
Heat and Mass Balance for Baking Process
}

\author{
El-Sayed G Khater* and Adel H Bahnasawy
}

Agricultural Engineering Department, Faculty of Agriculture, Benha University 13736, Egypt

\begin{abstract}
The main objective of this research was to develop a mathematical model of heat and mass balance of the bread baking process to predict the temperature and water content of bread at different heating temperatures and times. The model was able to predict the bread temperature and water content at different oven temperatures $(180,190,200,210$ and $220^{\circ} \mathrm{C}$ ). The results showed that the bread temperature and weight loss of bread increase with increasing oven temperature, when, the oven temperature increased from 180 to $220^{\circ} \mathrm{C}$, the temperature of bread increased from 112.73 to $168.49^{\circ} \mathrm{C}$ and the weight loss of bread increased from 22.40 to $52.46 \%$. The results also showed that the bread temperature and weight loss of bread increase with increasing time, this increment starts to decline after 18-20 min, until it reach equilibrium after $30 \mathrm{~min}$. The weight loss of bread increases with increasing bread temperature. It indicates that when the bread temperature increased from 20.00 to $131.69^{\circ} \mathrm{C}$, the weight loss of bread increased from 0.00 to $40.79 \%$ at $200^{\circ} \mathrm{C}$ oven temperature. The model was validated with an experimental data and showed a reasonable agreement with those measured, where; it ranged 20.00 to $131.69^{\circ} \mathrm{C}$ theoretically while it was from 25.00 to $119.00^{\circ} \mathrm{C}$ experimentally during the baking at $200^{\circ} \mathrm{C}$ oven temperature. The weight loss data was in a reasonable agreement with those measured, where; it ranged 0.00 to $40.79 \%$ theoretically while it was from 0.00 to $48.69 \%$ experimentally during the baking at $200^{\circ} \mathrm{C}$ oven temperature.
\end{abstract}

Keywords: Heat balance; Mass balance; Mathematical model; Bread temperature; Baking

\section{Introduction}

Baking is the final and most important step in bread production, and can be defined as the process which transforms dough, basically made of flour, water and leavening agents, in a food with unique sensory features by application of heat inside an oven. In particular, white or French bread is the most popular type of bread, and is distinguished for having a crunchy and golden-yellow (or brown) crust, a sponge and light crumb with soft texture and intermediate moisture, and a typical flavour. All these quality aspects are the result of a series of physical and chemical changes produced by simultaneous heat and mass transfer occurring within the product during baking [1-6].

The first bread was made around 10,000 years BC or over 12,000 years in the past, which may have been developed by deliberate experimentation with water and grain flour. Egyptians are the pioneers who make the art of bread making popular throughout the world. Control of the production and distribution of bread has been used as a means of exercising political influence over the populace for at least the last 2000 years. Even today, a shortage of bread is synonymous with hard times, while the promise of its service is used as rallying call for better life [2].

Simulation can be defined as the process of developing a model of a real system and carrying out experiments through the model, with the aim of studying, analyzing, designing or re-designing, controlling and predicting a certain real process. Besides the validation of the model, numerical simulation does not imply field experiments; it only includes the development of a mathematical model and computational effort, mostly more inexpensive than real tests. In addition, simulation gives the possibility of working under standardized operative conditions, minimizing the uncertainties of complex processes, especially those which are traditional non-automated processes. In this way, it will be very useful to have an accurate mathematical model for bread baking simulation [7].

There are several researchers have been studied the baking process, [8] studied of sponge cake batter baking process (Modeling and parameter estimation) and [9] developed a model of heat and mass transfer phenomena and quality changes during continuous biscuit baking using both deductive and inductive (neural network) modelling principles. [10,11] developed a simulation of bread making process using a direct 3D numerical method at microscale (Analysis of foaming phase during proofing, and Analysis of baking step). Also, [12] studied behavior of baking of semi-sweet short dough biscuits mathematically.

Bread is closely related to people's daily life and bread making is an important unit operation in food industry. Although people have practiced baking for a very long time, quantitative understanding of physical processes in baking is still very limited, therefore, understanding the physical processes of baking such as volume expansion, heating temperature, moisture change is the main aim of this work which could be achieved by developing a mathematical model of the heat and mass balance of the baking process to study the heating temperature and bread moisture content.

\section{Model Development}

The model includes the main distinguishing features of bread baking, i.e. the rapid heating of bread core and the development of a dry outer crust. Bread is modeled as a system containing three different regions: (1) crumb: wet inner zone, where temperature does not exceed $100^{\circ} \mathrm{C}$ and dehydration does not occur; (2) crust: dry outer zone, where temperature exceeds $100^{\circ} \mathrm{C}$ and dehydration occurs; (3) evaporation front: between the crumb and crust, where temperature is $100^{\circ} \mathrm{C}$ and water evaporates (liquid-vapour transition) $[7,13]$.

*Corresponding author: El-Sayed G Khater, Agricultural Engineering Department, Faculty of Agriculture, Benha University 13736, Egypt, Tel: +201324-670-34; E-mail: alsayed.khater@fagr.bu.edu.eg

Received September 23, 2014; Accepted November 28, 2014; Published December 02, 2014

Citation: Khater EG, Bahnasawy AH (2014) Heat and Mass Balance for Baking Process. J Bioprocess Biotech 4: 190 doi: 10.4172/2155-9821.1000190

Copyright: @ 2014 Khater EG, et al. This is an open-access article distributed under the terms of the Creative Commons Attribution License, which permits unrestricted use, distribution, and reproduction in any medium, provided the original author and source are credited. 
Citation: Khater EG, Bahnasawy AH (2014) Heat and Mass Balance for Baking Process. J Bioprocess Biotech 4: 190 doi: $10.4172 / 2155-$ 9821.1000190

Mathematically, the Moving Boundary Problem (MBP) is formulated using a physical approach, where the enthalpy jump corresponding to phase change is incorporated in the model by defining equivalent thermo physical properties [14]. Such definition states that evaporation occurs within a temperature range rather than at a fixed temperature. Other major assumptions of the model are the following:

- Bread is homogeneous and continuous; the concept of porous medium is included through effective or apparent thermo physical properties.

- Heat is transported by conduction from surface to bread core according to Fourier's law, but an effective thermal conductivity is used to incorporate the evaporation-condensation mechanism in heat transfer.

- Only liquid diffusion in the crumb and only vapour diffusion in the crust are assumed to occur [15].

- Volume change is neglected.

- Energy from oven ambient to bread surface is transferred by convection and radiation.

- Liquid water migrates from the core towards to the evaporation front under a water content gradient and liquid water flux is described by Fick's diffusion law.

- Water vapour migrates from the evaporation front to bread surface under a water vapour concentration gradient and mass flux is described by Fick's diffusion law.

- Water vapour is transferred to oven ambient through convective flux.

\section{Governing Equations}

Bread is considered as an infinite cylinder of radius $r$, so the problem is reduced to a single dimension via the axial symmetry assumption and it is assumed that the volume. For initial conditions, uniform temperature and water content are assumed. Figure 1 represents the heat and mass balance for bread. Heat balance include: heat conduction, heat convection and heat radiation.

\section{Heat balance equation}

$$
\rho \mathrm{C}_{\mathrm{P}} \frac{\partial T}{\partial t}=\frac{1}{r} \frac{\partial}{\partial r}\left(r k \frac{\partial T}{\partial r}\right)
$$

\section{Boundary conditions}

The heat arrives to the bread surface by convection and radiation, and is balanced by conduction inside the bread:

$$
-k \frac{\partial T}{\partial r}=h\left(T_{s}-T_{\infty}\right)+\varepsilon \sigma\left(\mathrm{T}_{\mathrm{s}}^{4}-T_{\infty}^{4}\right)
$$

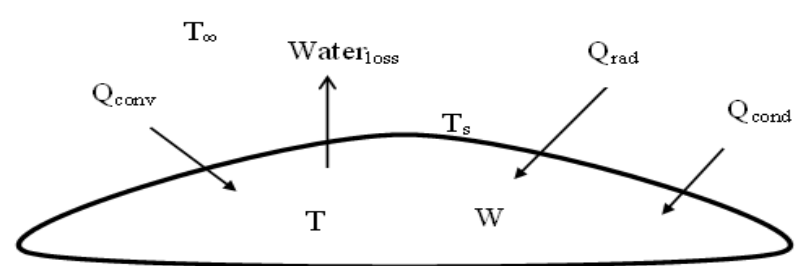

Figure 1: Heat and mass balance of bread

\section{Mass balance equation}

$$
\frac{\partial W}{\partial t}=\frac{1}{r} \frac{\partial}{\partial r}\left(r D \frac{\partial W}{\partial r}\right)
$$

\section{Boundary conditions}

The water migrating towards the bread surface is balanced by convective flux:

$$
\begin{aligned}
& -D \rho_{s} \frac{\partial W}{\partial t}=k_{g}\left(\mathrm{P}_{\mathrm{s}}\left(T_{s}\right)-P_{\infty}\left(T_{\infty}\right)\right) \\
& p_{s}=\mathrm{a}_{\mathrm{w}} \mathrm{p}_{\text {sat }}\left(\mathrm{T}_{\mathrm{s}}\right) \\
& p_{\infty}=\left(\frac{R H}{100}\right) \mathrm{p}_{\text {sat }}\left(\mathrm{T}_{\infty}\right)
\end{aligned}
$$

At the center, i.e. $r=0$

$$
\begin{aligned}
& \frac{\partial T}{\partial t}=0 \\
& \frac{\partial W}{\partial t}=0
\end{aligned}
$$

\section{Thermo physical properties}

According to the MBP formulation, equivalent thermo physical properties are defined including the phase transition occurring during the process, i.e. an equivalent property is valid for dough/ crumb and crust $[7,16]$.

\section{Specific heat}

$$
\begin{aligned}
& C_{p}(T, W)=C_{p}^{*}(\mathrm{~T}, \mathrm{~W})+\lambda_{\mathrm{v}} \mathrm{W} \delta \\
& C_{p}^{*}(\mathrm{~T}, \mathrm{~W})=C_{p, s}(\mathrm{~T})+\mathrm{WC}_{\mathrm{p}, \mathrm{w}}(\mathrm{T}) \\
& \mathrm{C}_{\mathrm{p}, \mathrm{s}}=5 T+25 \\
& \mathrm{C}_{\mathrm{p}, \mathrm{w}}=\left(5.207-73.17 \times 10^{-4} T+1.35 \times 10^{-5} T^{2}\right) \times 1000
\end{aligned}
$$

Latent heat evaporation is calculated with the following set of equations [10]:

$$
\lambda_{v}=(2502535.259-212.56384(T-273))
$$

\section{Water activity}

$$
a_{w}(\mathrm{~T}, \mathrm{~W})=\left(\left(\frac{100 W}{\exp (-0.0056 T+5.5)}\right)^{-1 / 0.38}+1\right)^{-1}
$$

The heat transfer coefficient (h) is a model input for process simulation, and the mass transfer coefficient $(\mathrm{kg})$ is determined by using the Chilton-Colburn (or heat-mass) analogy and a correction factor [7]:

$$
\begin{aligned}
\frac{h}{k_{g}^{*}} & =\frac{\mathrm{M}_{\text {air }}}{\mathrm{M}_{\mathrm{w}}} \mathrm{P}_{\mathrm{atm}} \mathrm{C}_{\mathrm{p}, \text { air }}\left(\frac{\mathrm{Sc}}{\mathrm{Pr}}\right)^{2 / 3} \\
\mathrm{k}_{\mathrm{g}} & =7.83 \times 10^{-3} \mathrm{k}_{\mathrm{g}}^{*} \\
\mathrm{Sc} & =\frac{v}{\mathrm{D}}
\end{aligned}
$$


Citation: Khater EG, Bahnasawy AH (2014) Heat and Mass Balance for Baking Process. J Bioprocess Biotech 4: 190 doi: $10.4172 / 2155-$ 9821.1000190

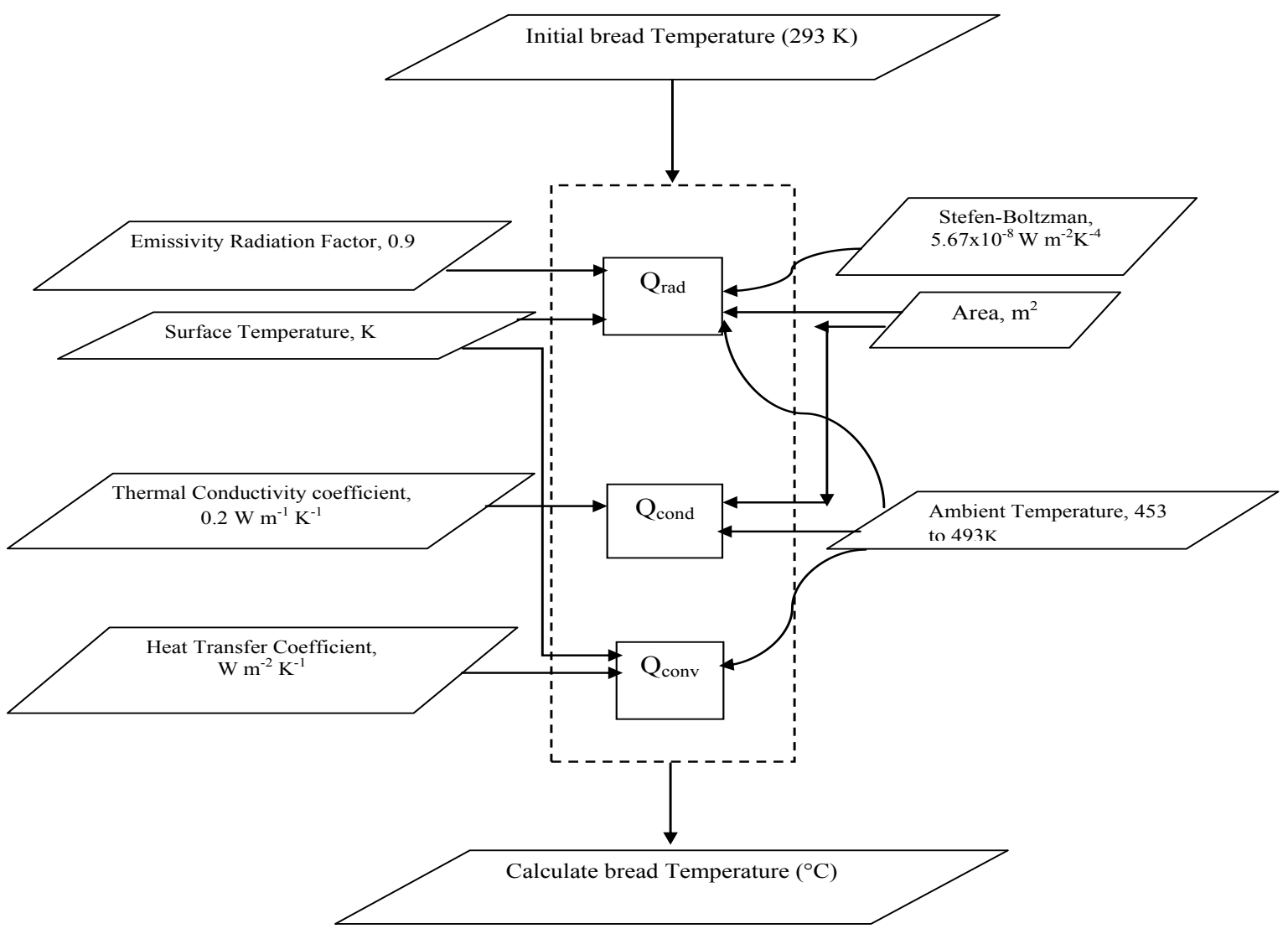

Figure 2: Flowchart of the mass balance of bread

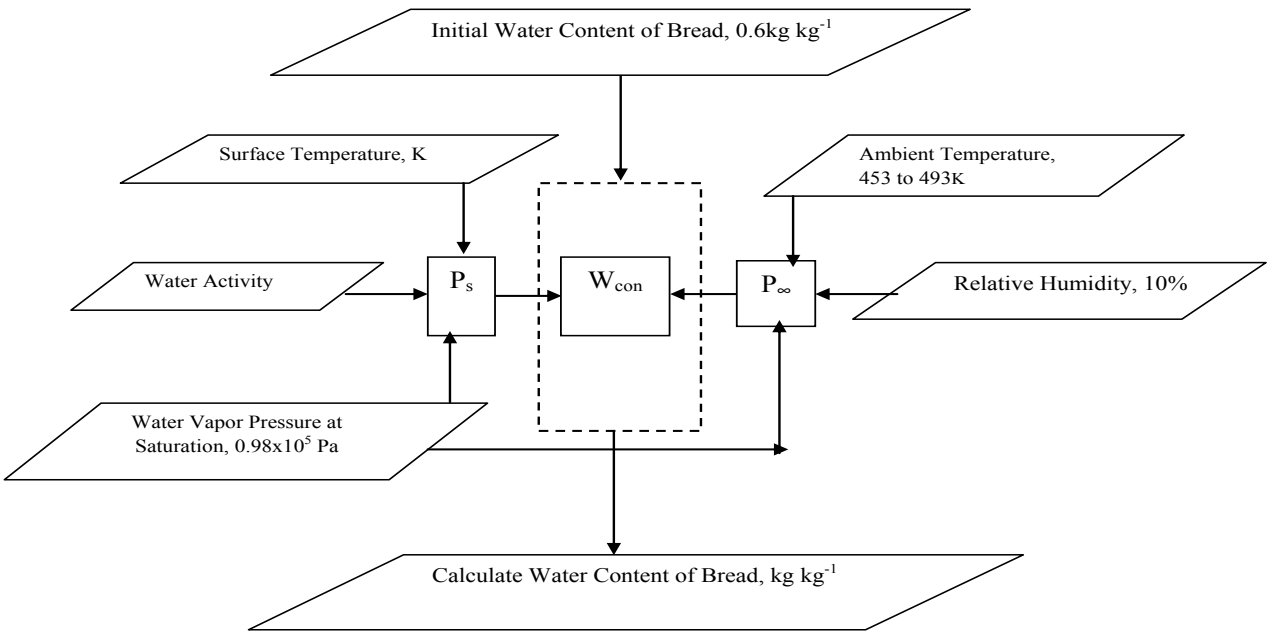

Figure 3: Flowchart of the mass balance of bread

$$
\operatorname{Pr}=\frac{v}{\alpha}
$$

Regarding heat transfer by radiation, the emissivity of bread surface is considered equal to $0.9[17,18]$.

All computational procedures of the model were carried out using
Excel spreadsheet. The computer program consisted of two parts in addition to the input parts. The first part was devoted to heat balance for predicting the temperature at the middle cross-section of bread. The second part was devoted to mass balance for predicting water content of bread. Figures 2 and 3 show the flowcharts of the model steps and sequences. They are representing the heat and mass balance and the 
Citation: Khater EG, Bahnasawy AH (2014) Heat and Mass Balance for Baking Process. J Bioprocess Biotech 4: 190 doi: $10.4172 / 2155-$ 9821.1000190

Page 4 of 6

\begin{tabular}{|c|c|c|c|}
\hline Parameter & Units & Value & Source \\
\hline Thermal conductivity, $\mathrm{k}$ & $\mathrm{W} \mathrm{m}^{-1} \mathrm{~K}^{-1}$ & 0.20 & {$[6]$} \\
\hline Bread density, $\rho$ & $\mathrm{kg} \mathrm{m}^{-3}$ & 321.31 & {$[18]$} \\
\hline Density of solid, $\rho_{\mathrm{s}}$ & $\mathrm{kg} \mathrm{m}^{-3}$ & 241.76 & {$[18]$} \\
\hline Water diffusion coefficient, $\mathrm{D}$ & $\mathrm{m}^{2} \mathrm{~s}^{-1}$ & $1 \times 10^{-4}$ & {$[19]$} \\
\hline Water vapor pressure at saturation, $\mathrm{P}_{\text {sat }}$ & $\mathrm{Pa}$ & $0.98 \times 10^{5}$ & {$[20]$} \\
\hline Mass transfer coefficient, $\mathrm{k}_{\mathrm{g}}^{*}$ & $\mathrm{~kg} \mathrm{~Pa}^{-1} \mathrm{~m}^{-2} \mathrm{~s}^{1}$ & $1.1 \times 10^{-7}$ & {$[5]$} \\
\hline Emissivity, $\varepsilon$ & & 0.90 & {$[18]$} \\
\hline Kinematic viscosity, $\mathrm{v}$ & $\mathrm{m}^{2} \mathrm{~s}^{-1}$ & $28.86 \times 10^{-6}$ & {$[21]$} \\
\hline Thermal diffusivity, $\alpha$ & $\mathrm{m}^{2} \mathrm{~s}^{-1}$ & $1.17 \times 10^{-7}$ & {$[21]$} \\
\hline Bread radius, $\mathrm{r}$ & $\mathrm{M}^{-1}$ & 0.03 & \\
\hline Relative humidity, $\mathrm{RH}$ & $\%$ & 10 & \\
\hline Delta-type function, $\delta$ & & 1 & \\
\hline Stefan-Boltzmann constant, $\sigma$ & $\mathrm{W} \mathrm{m}^{-2} \mathrm{~K}^{-4}$ & $5.67 \times 10^{-8}$ & \\
\hline Initial temperature & $\mathrm{K}^{-1}$ & 293 & \\
\hline Initial water content & $\mathrm{kg} \mathrm{kg}^{-1}$ & 0.6 & \\
\hline Table $1:$ The oarameters & & \\
\hline
\end{tabular}

Table 1: The parameters used in the heat and mass balance.

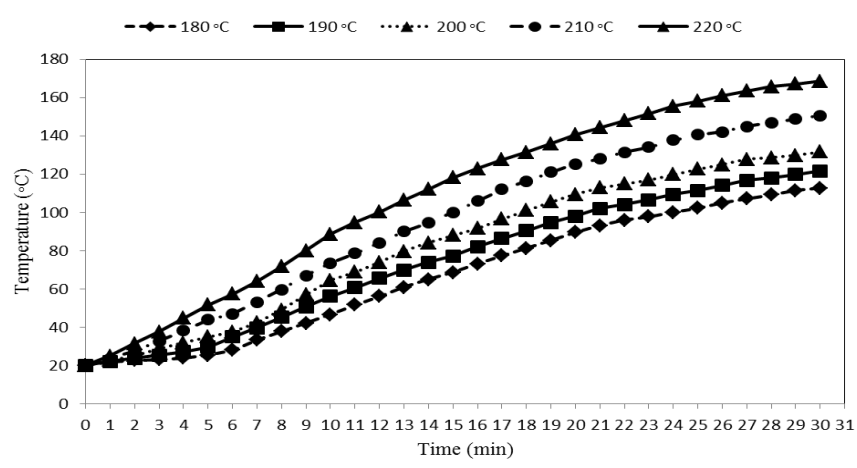

Figure 4: The predicted temperature of the bread crust at different oven temperatures.

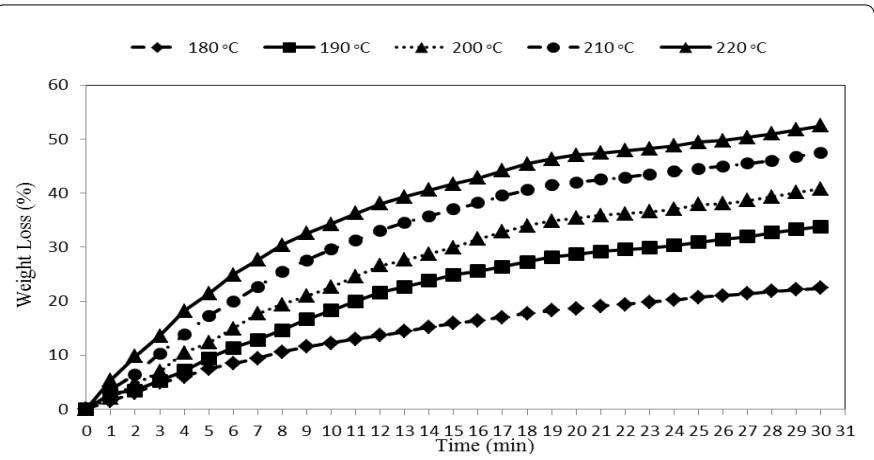

Figure 5: The predicted bread weight loss at different oven temperatures.

calculation steps of their model. Table 1 show the parameters used in the model.

\section{Results and Discussions}

\section{Model experimentation}

Temperature: Figure 4 shows the predicted temperature of the crust of bread process during the baking at different oven temperatures (180, $190,200,210$ and $220^{\circ} \mathrm{C}$ ). The results indicate that the bread temperature increases with increasing oven temperature. It also indicates that when the oven temperature increased from 180 to $220^{\circ} \mathrm{C}$, the temperature at the crust of bread increased from 112.73 to $168.49^{\circ} \mathrm{C}$. The results show that the temperature increases with increasing time, it increased from 20 to $112.73^{\circ} \mathrm{C}$ when the time increased from 0 to $30 \mathrm{~min}$ at oven temperature $180^{\circ} \mathrm{C}$. On the other hand, the temperature increased from 20 to $116.18^{\circ} \mathrm{C}, 20$ to $131.69^{\circ} \mathrm{C}, 20$ to $144.05^{\circ} \mathrm{C}$ and 20 to $168.49^{\circ} \mathrm{C}$ at oven temperature $190,200,210$ and $220^{\circ} \mathrm{C}$, respectively. These results were in agreement with those obtained by [7,16,22-25].

It is worth to note that the bread temperature reached $62.6 \%$ of the heat balance at temperature of $180^{\circ} \mathrm{C}$, while it reached $76.7 \%$ of the heat balance at $220^{\circ} \mathrm{C}$ oven temperature, this could lead to that using the higher temperature $\left(200-220^{\circ} \mathrm{C}\right)$ more effective in utilization of heat energy. Multiple regression analysis was carried out to find a relationship between baking time, oven temperature and the bread temperature. The best form obtained was as follows:

$$
\mathrm{T}_{\mathrm{P}}=-210.217+4.45 t+1.137 T_{o}
$$

Weight loss: Figure 5 shows the predicted bread weight loss during the baking process at different oven temperatures $(180,190$, 200,210 and $220^{\circ} \mathrm{C}$ ). The results indicate that the weight loss increases with increasing oven temperature. It indicates that when the oven temperature increased from 180 to $220^{\circ} \mathrm{C}$, the bread weight loss increased from 22.40 to $52.46 \%$. The results show that the weight loss increases with increasing time; this increment starts to decline after 18$20 \mathrm{~min}$, until it reached equilibrium after $30 \mathrm{~min}$. It increased from 0 to $22.40 \%$ when the time increased from 0 to $30 \mathrm{~min}$ at oven temperature $180^{\circ} \mathrm{C}$. On the other hand, the weight loss increased from 0 to $52.46 \%$ at oven temperature $220^{\circ} \mathrm{C}$. These results were in agreement with those obtained by $[16,25]$. Weight loss of bread decrease by $22.40,33.79$, $40.49,47.46$ and $52.46 \%$ for the oven drying temperatures of 180,190 , 200,210 and $220^{\circ} \mathrm{C}$, respectively.

At the lower oven temperature $\left(180^{\circ} \mathrm{C}\right)$, the weight loss reached $22.40 \%$ of the total weight which is lower by about $17.60 \%$ that should be lost to reach the recommended weight loss of the bread $(40.00 \%$, [26]). At the higher oven temperature $\left(220^{\circ} \mathrm{C}\right)$, the weight loss reached $52.46 \%$ of the total weight which is higher by about $12.46 \%$ that should be lost to reach the recommended weight loss of the bread (40\%). Multiple regression analysis was carried out to find a relationship between baking time, oven temperature and the bread weight loss. The best form obtained was as follows:

$$
\mathrm{W} L_{\mathrm{P}}=-103.106+1.213 t+0.555 T_{o}
$$

Relationship between the average bread temperature and average weight loss of bread

Figure 6 shows the relationship between the predicted average

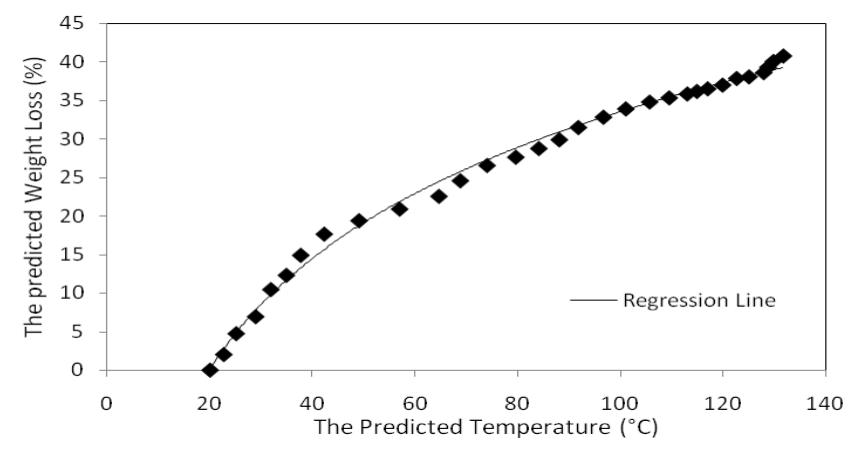

Figure 6: The relationship between the predicted average bread temperature and the predicted average weight loss of bread at the average oven temperature. 
Citation: Khater EG, Bahnasawy AH (2014) Heat and Mass Balance for Baking Process. J Bioprocess Biotech 4: 190 doi: $10.4172 / 2155-$ 9821.1000190

Page 5 of 6

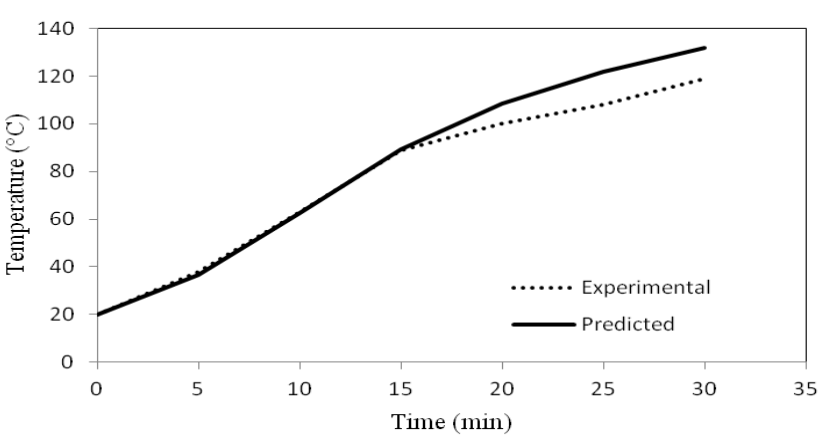

Figure 7: The predicted and the experimental temperatures of beard during the baking.

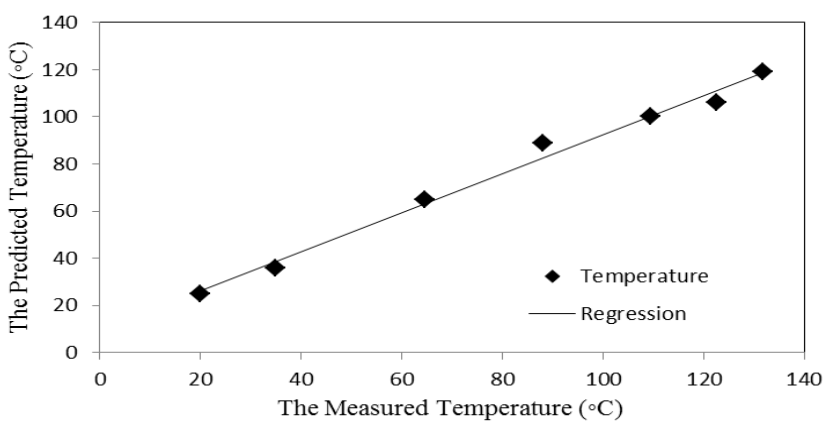

Figure 8: The comparison between the predicted and the experimental temperatures of bead during the baking.

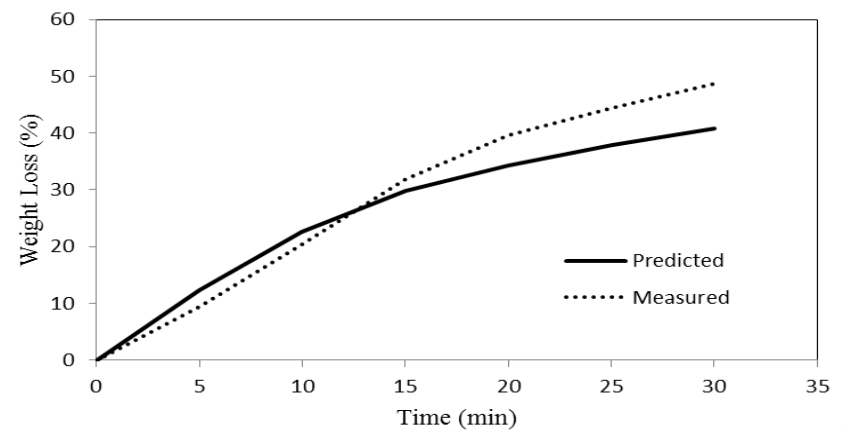

Figure 9: The predicted and the experimental weight losses of bread during the baking

bread temperature and the predicted average weight loss of bread at the average oven temperature. The average weight loss of bread increases with increasing average bread temperature, the average weight loss increased linearly during the temperature range of $20-100^{\circ} \mathrm{C}$, then increment. It indicates that when the average bread temperature increased from 20.00 to $137.03^{\circ} \mathrm{C}$, the average weight loss of bread increased from 0.00 to $39.38 \%$ at the average oven temperature.

The relationship between the predicted average bread temperature and the predicted average weight loss of bread at average oven temperature is shown in figure 6 . This relationship is expressed by the following equation:

$$
W L_{P}=20.47 \ln \mathrm{T}_{\mathrm{P}}-61.3226 \quad \mathrm{R}^{2}=0.99
$$

\section{Model validation}

The model was validated using the data published by Purlis and Salvadori [7].

\section{Temperature}

Figure 7 shows the predicted and the experimental temperatures of bread during the baking. It could be seen that, the temperature by the model was in a reasonable agreement with those measured, where; it ranged 20.00 to $131.69^{\circ} \mathrm{C}$ theoretically while it was from 20.00 to $119.00^{\circ} \mathrm{C}$ experimentally during the baking at $200^{\circ} \mathrm{C}$ oven temperature.

Regression analysis was carried out to find a relationship between the predicted and experimental bread temperatures and the most suitable form is shown as follows (Figure 8):

$$
\mathrm{T}_{\mathrm{P}}=1.1456 \mathrm{~T}_{\mathrm{M}}-9.4539 \quad \mathrm{R}^{2}=0.99
$$

\section{Weight loss}

Figure 9 shows the predicted and the experimental weight losses of bread during the baking. It could be seen that, the weight loss by the model was in a reasonable agreement with those measured during the period between $0-15 \mathrm{~min}$, where it ranged from 0.00 to $33.16 \%$ then there were variations between the predicted and experimental data, where the model results were lower than those of the experimental, where it ranged from 33.16 to $49.79 \%$ theoretically while it was from 0.00 to $48.69 \%$ experimentally during the baking at $200^{\circ} \mathrm{C}$ oven temperature in the period between 15-30 min, this underestimation of bread weight loss is probably due to not considering the evaporationcondensation contribution in this process.

The variations between the predicted and the experimental are shown in figure 10. The relationship between the predicted and measured temperatures is expressed by the following equation:

$$
\mathrm{WL}_{\mathrm{P}}=1.2308 \mathrm{WL}_{\mathrm{M}}-3.5117 \quad \mathrm{R}^{2}=0.97
$$

\section{Conclusions}

A mathematical model for the baking process was developed successively according to heat balance and mass balance to study the bread temperature and water content at different oven temperatures. Also the model was validated using an experimental data from [7]. The most important results obtained can be summarized as follows:

- The model showed that the predicted bread temperature increases with increasing oven temperature, where, the oven temperature increased from 180 to $220^{\circ} \mathrm{C}$, the temperature of the crust of bread increased from 112.73 to $168.49^{\circ} \mathrm{C}$.

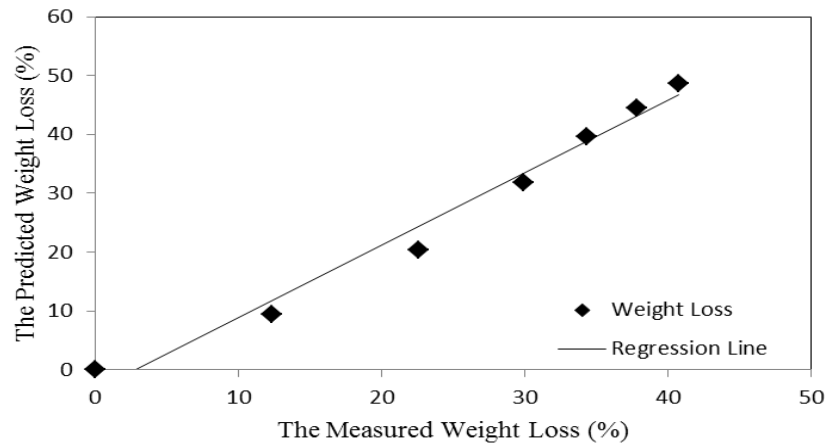

Figure 10: The comparison between the predicted and the experimental weight losses of bread during the baking. 
Citation: Khater EG, Bahnasawy AH (2014) Heat and Mass Balance for Baking Process. J Bioprocess Biotech 4: 190 doi: $10.4172 / 2155-$ 9821.1000190

- The model showed that the temperature increases with increasing time, where, it increased from 20 to $112.73^{\circ} \mathrm{C}$ when the time increased from 0 to $30 \mathrm{~min}$ at oven temperature $180^{\circ} \mathrm{C}$. On the other hand, the temperature increased from 20 to $168.49^{\circ} \mathrm{C}$ at oven temperature $220^{\circ} \mathrm{C}$.

- The model showed that the weight loss increases with increasing oven temperature, where, the oven temperature increased from 180 to $220^{\circ} \mathrm{C}$, the weight loss of bread increased from 22.40 to $52.46 \%$. The model showed that the weight loss increases with increasing time, this increment starts to decline after 18$20 \mathrm{~min}$, until it reach equilibrium after $30 \mathrm{~min}$. It increased from 0 to $22.40 \%$ when the time increased from 0 to $30 \mathrm{~min}$ at oven temperature $180^{\circ} \mathrm{C}$. On the other hand, the weight loss increased from 0 to $52.46 \%$ at oven temperature $220^{\circ} \mathrm{C}$.

- The predicted bread temperature was in a reasonable agreement with the experimental temperature with a coefficient of determination of 0.98 . The bread temperature ranged from 20.00 to $131.69^{\circ} \mathrm{C}$ theoretically while it was from 25.00 to $119.00^{\circ} \mathrm{C}$ experimentally during the baking at $200^{\circ} \mathrm{C}$ oven temperature.

- The predicted weight loss of bread was in a reasonable agreement with the experimental weight loss of bread with a coefficient of determination of 0.97 . The weight loss of bread ranged from 0.00 to $40.79 \%$ theoretically while it was from 0.00 to $48.69 \%$ experimentally during the baking at $200^{\circ} \mathrm{C}$ oven temperature.

\section{Nomenclature}

\section{$\rho$ bread density, $\mathrm{kg} \mathrm{m}^{-3}$}

$\mathrm{C}_{\mathrm{p}}$ specific heat of bread, $\mathrm{J} \mathrm{kg}^{-1} \mathrm{~K}^{-1}$

$\mathrm{T}^{\mathrm{p}}$ temperature of bread at as a function of time, $\mathrm{K}$

$t$ time, $s$

$r$ bread radius, $m$

$\mathrm{k}$ bread thermal conductivity, $\mathrm{W} \mathrm{m}^{-1} \mathrm{~K}^{-1}$

$\mathrm{h}$ heat transfer coefficient, $\mathrm{W} \mathrm{m^{-2 } \mathrm { K } ^ { - 1 }}$

$T$ surface temperature, $\mathrm{K}$

$\mathrm{T}_{\infty}$ ambient temperature, $\mathrm{K}$

$\varepsilon$ emissivity, dimensionless

$\sigma$ Stefan-Boltzmann constant,

dimensionless

W water content of bread, $\mathrm{kg} \mathrm{kg}^{-1}$

D water diffusion coefficient, $\mathrm{m}^{2} \mathrm{~s}^{-1} \quad$ Pr Prandlt number, dimensionless

$\mathrm{kg}_{\mathrm{g}}$ corrected mass transfer coefficient, $\mathrm{kg}$ v kinematic viscosity, $\mathrm{m}^{2} \mathrm{~s}^{-1}$

$\mathrm{Pa}^{-1} \mathrm{~m}^{-2} \mathrm{~s}^{-1} \quad \alpha$ thermal diffusivity, $\mathrm{m}^{2} \mathrm{~s}^{-1}$

$\mathrm{p}_{\mathrm{s}}$ water vapour pressure of the air at the $\mathrm{T}_{\mathrm{P}}$ predicted bread temperature, ${ }^{\circ} \mathrm{C}$

bread

surface, $\mathrm{Pa}$

$\mathrm{T}_{\mathrm{P}}$ predicted bread temperature, ${ }^{\circ} \mathrm{C}$

water vapour pressure of the air at the $\mathrm{T}$ oven temperature, ${ }^{\circ} \mathrm{C}$

oven

ambient, $\mathrm{Pa}$

$\mathrm{WL}_{p}$ predicted weight loss, $\%$

$\mathrm{WL}_{\mathrm{M}}$ measured weight loss, $\%$

\section{References}

1. Sablani SS, Marcotte M, Baik OD, Castaigne F (1998) Modeling of simultaneous heat and water transport in the baking process. LWT - Food Science and Technology 31: 201-209.

2. Scanlon MG, Zghal MC (2001) Bread properties and crumb structure. Food Research International 34: 841-864.

3. Mondal A, Datta AK (2008) Bread baking - a review. Journal of Food Engineering 86: $465-474$

4. Vanin FM, Lucas T, Trystram G (2009) Crust formation and its role during bread baking. Trends in Food Science \& Technology 20: 333-343.

5. Purlis E, Salvadori VO (2009) Modelling the browning of bread during baking. Food Research International 42: 865-870.
6. Purlis E (2010) Browning development in bakery products-A review. Journal of Food Engineering 99: 239-249.

7. Purlis E, Salvadori VO (2009b) Bread baking as a moving boundary problem Part 2: model validation and numerical simulation. Journal of Food Engineering 91: 434-442.

8. Lostie M, Peczalski R, Andrieu J, Laurent M (2002) Study of sponge cake batter baking process.II. Modeling and parameter estimation. Journal of Food Engineering, 55: 349-357.

9. Broyart B, Trystram G (2003) Modelling of heat and mass transfer phenomena and quality changes during continuous biscuit baking using both deductive and inductive (neural network) modelling principles. Food and Bioproducts Processing 81: 316-326.

10. Bikard J, Coupez T, Valle GD, Vergnes B (2008) Simulation of bread making process using a direct 3D numerical method at microscale: Analysis of foaming phase during proofing. Journal of Food Engineering 85: 259-267.

11. Bikard J, Coupez T, Della Valle G, Vergnes B (2012) Simulation of bread making process using a direct 3D numerical method at microscale: Analysis of baking step. Int J Mater Form 5: 11-24.

12. Baldino N, Gabriele D, Lupi FR, de Cindio B, Cicerelli L (2014) Modeling of baking behavior of semi-sweet short dough biscuits. Innovative Food Science and Emerging Technologies 25: 40-52.

13. Purlis E (2012) Baking process design based on modeling and simulation Towards optimization of bread baking. Food Control 27: 45-52.

14. Bonacina C, Comini G, Fasano A, Primicerio M (1973) Numerical solution of phase-change problems. International Journal of Heat and Mass Transfer 16 1825-1832.

15. Luikov AV (1975) Systems of differential equations of heat and mass transfer in capillary-porous bodies (review). International Journal of Heat and Mass Transfer 18: 1-14.

16. Purlis E, Salvadori VO (2009a) Bread baking as a moving boundary problem. Part 1: mathematical modelling. Journal of Food Engineering 91: 428-433.

17. Anonymous (1992) ASAE Standards. 39th edition. American Society of Agricultural Engineers. St. Joseph, MI. 781 pages.

18. Hamdami N, Monteau JY, Le Bail A (2004) Heat and mass transfer in par-baked bread during freezing. Food Research International 37: 477-488.

19. Rogers EK, Brimel CJ (2005) Instrumentation and sensors for the food industry. 2nd edition. Woodhead Publishing Limited. Cambridge, England.

20. Eckert ER, RM Drake (1959) Heat and Mass Transfer. 2nd edition. McGrawHill, New York, USA.

21. Magee TRA, Branshurg T (1995) Measurement of thermal diffusivity of potato malt bread and wheat flour. Journal of Food Engineering 25: 223-232.

22. Zhang J, Datta AK (2006) Mathematical modelling of bread baking process. Journal of Food Engineering 75: 78-89.

23. Wang R, Zhou W, Jiang X (2008) Mathematical modeling of the stability of green tea catechin epigallocatechin gallate (EGCG) during bread baking Journal of Food Engineering 87: 505-513.

24. Mondal A, Datta AK (2010) Two-dimensional CFD model and simulation of crustless bread baking process. Journal of Food Engineering 99: 168-174.

25. Purlis E (2011) Bread baking: Technological considerations based on process modeling and simulation. Journal of Food Engineering 103: 92-102.

26. Bakers Journal (2001) The effect of hard water and soft water on baked goods. 